\title{
Simulasi Kinerja Motor BLDC untuk Merancang Sistem Kelistrikan Mobil Hemat Energi Menggunakan Simulink
}

\author{
Simulation of BLDC Motor Performance for Designing an \\ Electrical System of Energy-Efficient Car Using Simulink
}

\author{
SATRIO WAHYUBRAMANTO ${ }^{1 *}$, SHEILA TOBING ${ }^{1}$, YOHANES ADEATMA \\ ANTONIO $^{1}$
}

\begin{abstract}
Abstrak
Kontes Mobil Hemat Energi (KMHE) merupakan lomba tingkat nasional yang diselenggarakan oleh Kementerian Riset dan Teknologi Indonesia yang bertujuan untuk mewadahi kreativitas mahasiswa seluruh Indonesia dalam merancang, membangun, menguji dan menyelenggarakan kompetisi mobil hemat energi yang aman dan ramah lingkungan. Peserta dari kegiatan ini adalah seluruh mahasiswa teknik di Indonesia. Penelitian ini membahas mengenai rancang bangun sistem kelistrikan mobil hemat energi yang telah sesuai regulasi KMHE 2019. Metode yang digunakan dalam penelitian ini adalah melalui simulasi Simulink MATLAB dengan menggunakan sistem kontrol Proportional Integral Derivative (PID). Hasil simulasi dengan program Simulink MATLAB R2020b menunjukkan bahwa motor BLDC dengan kecepatan putar 100-900 rpm menghasilkan torsi motor sebesar $30 \mathrm{Nm}$ dan memiliki daya sekitar $960 \mathrm{~W}$. Hal ini menunjukkan bahwa motor BLDC telah melebihi kebutuhan perancangan mobil listrik.
\end{abstract}

Kata Kunci: KMHE, motor BLDC, ramah lingkungan, sistem kelistrikan, torsi motor.

\begin{abstract}
Kontes Mobil Hemat Energi (KMHE) is a national-level competition organized by the Indonesian Ministry of Research and Technology. KMHE aims to accommodate students' creativity throughout Indonesia in designing, building, testing, and competing for energy-efficient cars that are safe and environmentally friendly. The participants of this competition are all engineering students from all over Indonesia. This research discusses the design of an energy-efficient car electrical system according to the $2019 \mathrm{KMHE}$ regulations. The method used in this research is through Simulink MATLAB simulation using a Proportional Integral Derivative (PID) control system. The simulation results with the MATLAB R2020b Simulink program show that a BLDC motor with a rotating speed of 100-900 rpm produces a motor torque of $30 \mathrm{Nm}$ and has a power of about $960 \mathrm{~W}$. This shows that the BLDC motor has exceeded the design needs of an electric car.
\end{abstract}

Keywords: BLDC motor, electrycal system, environmentally friendly, KMHE, motor torque.

\section{PENDAHULUAN}

Kementerian Riset dan Teknologi Indonesia telah menyelenggarakan lomba tingkat nasional yang berjudul Kontes Mobil Hemat Energi (KMHE). Peserta dari kegiatan ini merupakan mahasiswa teknik dari seluruh Indonesia. Kontes ini bertujuan untuk mewadahi kreativitas mahasiswa di seluruh Indonesia dalam merancang, membangun, menguji dan menyelenggarakan kompetisi mobil hemat energi yang aman dan ramah lingkungan. Melalui perlombaan ini, mahasiswa dapat mengaplikasikan seluruh ilmu yang telah dipelajari pada masa kuliah, meningkatkan kreativitas serta melatih soft skill dan hard skill.

Tujuan dari penelitian ini adalah untuk melakukan simulasi dengan Simulink mengenai penggunaan motor BLDC, serta rancang bangun sistem kelistrikan mobil hemat energi yang

${ }^{1}$ Prodi Teknik Mesin Universitas Katolik Indonesia Atma Jaya Banten, 021-80827200;

*Penulis Korespondensi: Tel/Faks: 081250876102; Surel: satrio.2016041034@student.atmajaya.ac.id 
akan digunakan untuk mengikuti Kontes Mobil Hemat Energi (KMHE) 2021. Perancangan sistem kelistrikan akan mengikuti regulasi KMHE karena ketentuan regulasi menjadi syarat utama mobil listrik yang dirancang dapat mengikuti perlombaan dan aman untuk dikendarai oleh pengemudi (Universitas Negeri Malang 2019). Motor BLDC menggunakan jenis komutator listrik daripada komutator mekanis. Fitur ini membuktikan bahwa motor BLDC lebih andal dari motor DC. Pada motor BLDC, magnet rotor menghasilkan fluks magnet yang dapat membuat efisiensi menjadi lebih tinggi (Madur dan Debre 2017).

Kategori yang dilombakan pada KMHE terbagi menjadi dua jenis yaitu, Prototype dan Urban Concept. Untuk Prototype, kendaraan yang dibuat memiliki desain khusus yang mengoptimalkan aerodinamikanya. Sedangkan pada kategori Urban Concept, kendaraan yang dibuat memiliki tampilan seperti mobil pada umumnya dan sesuai untuk berkendara di jalan. Kelas mesin penggerak yang digunakan untuk dua kategori tersebut dapat menggunakan Motor Pembakaran Dalam (MPD) Gasoline, MPD Diesel, MPD Etanol dan Motor Listrik. Tim Workshop Mesin (WSM) mengikuti kategori Urban Concept dengan mesin penggerak Motor Listrik.

\section{METODE}

Metode yang digunakan dalam penelitian ini adalah melalui simulasi Simulink MATLAB dengan menggunakan sistem kontrol Proportional Integral Derivative (PID). Simulasi penelitian dilakukan dengan memerhatikan parameter yang dibutuhkan pada perhitungan daya, torsi dan jumlah putaran per menit (rotations per minute (rpm)) yang ada. Voltase yang diberikan yaitu $48 \mathrm{~V}$ dan desired input yaitu berkisar antara 100-600 rpm. Hal ini sesuai dengan spesifikasi motor BLDC yang dimiliki tim WSM yang memiliki $600 \mathrm{rpm}$ dan daya $1000 \mathrm{~W}$. Melalui simulasi akan dilihat respon sistem dari motor BLDC dan juga dapat dilihat hasil torsi yang terjadi pada simulasi. Tahap penelitian mengikuti diagram alir yang dapat dilihat pada Gambar 1.

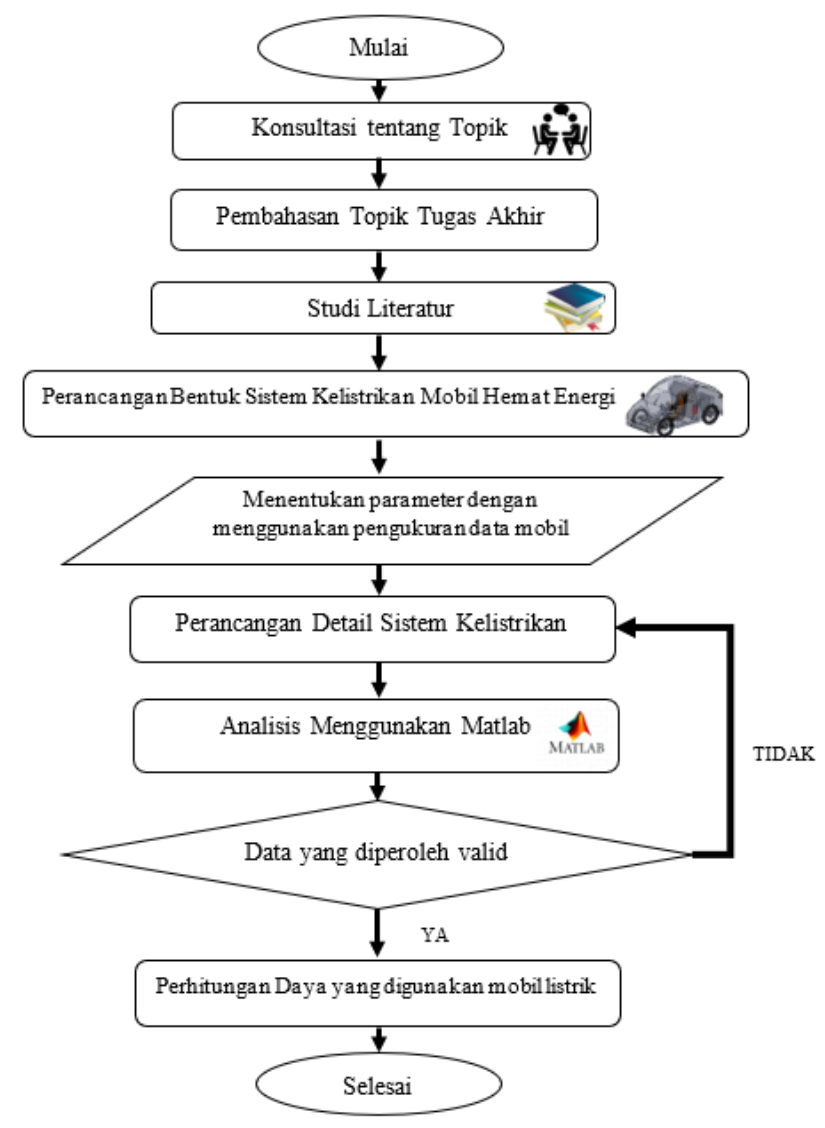

Gambar 1 Diagram Alir Penelitian. 
Dasar pemikiran dalam pemilihan motor listrik sebagai penggerak mobil listrik adalah bahwa motor listrik tersebut harus mampu menghasilkan torsi starting yang tinggi dengan arus yang rendah (Carryer et al. 2011). Asumsi dilakukan berdasarkan penelitian Universitas Florida mengenai mobil pada Shell Eco Marathon (Carryer et al. 2011), telah disesuaikan dengan kondisi kendaraan dan lingkungan di lokasi penyelenggaraan KMHE 2019. Hal ini dilakukan agar dapat memenuhi tujuan dan batasan masalah yang ada, berikut ini merupakan perhitungan sesuai dengan parameter yang ada (Tabel 1).

Tabel 1 Parameter Perhitungan yang digunakan (Carryer et al. 2011)

\begin{tabular}{lc}
\hline \multicolumn{1}{c}{ Parameter } & Nilai \\
\hline Frontal Area of Car $(S)$ & $1.69\left(\mathrm{~m}^{2}\right)$ \\
Percent Grade $\left(\mathrm{P}_{\mathrm{G}}\right)$ & 3 \\
Vehicle Mass $(m)$ & $200(\mathrm{~kg})$ \\
Drivetrain Efficiency & 0.8 \\
Tire Rolling Resistance coefficient $\left(C_{r r}\right)$ & 0.004 \\
Brake and steering resistance $\left(C_{B S R}\right)$ & 0.003 \\
Drag Coefficient $\left(C_{D}\right)$ & 0.3 \\
Air Density $(\rho)$ & $1.225\left(\mathrm{~kg} / \mathrm{m}^{3}\right)$ \\
Wheel Radius & $0.401(\mathrm{~m})$ \\
\hline
\end{tabular}

Beberapa gaya luar yang bekerja pada mobil terdiri dari gaya akibat gesekan udara (Fair_resistance), gaya akibat hambatan saat bergulir (Frolling_resistance), gaya akibat berat paralel mobil pada jalanan miring (Fincline) (Acosta et al. 2012). Jumlah dari gaya-gaya tersebut merupakan gaya drag yang bekerja pada mobil (Persamaan 1-5).

$$
\begin{aligned}
& F_{\text {air_resistance }}=0,5 \times C_{D} \times A \times \rho \times V^{2} \\
& F_{\text {rolling_resistance }}=m g\left(C_{r r}+C_{B S R}\right) \\
& F_{\text {incline }}=m \times g \times P_{G} \\
& F_{\text {drag }}=\Sigma F=F_{\text {air_resistance }}+F_{\text {rolling_resistance }}+F_{\text {incline }} \\
& P_{\text {constant }}=F_{\text {drag }} \times V
\end{aligned}
$$

Tabel 2 Data Kebutuhan Daya Mobil

\begin{tabular}{cccccc}
\hline $\begin{array}{c}\text { Kecepatan }(\text { V }) \\
\mathrm{km} / \mathrm{jam}\end{array}$ & $\begin{array}{c}\text { Fair_resistance } \\
(\mathrm{N})\end{array}$ & $\begin{array}{c}\text { Frolling_resistance } \\
(\mathrm{N})\end{array}$ & Fincline $(\mathrm{N})$ & Fdrag $(\mathrm{N})$ & Pconstant $(\mathrm{N})$ \\
\hline 10 & 2.382723 & 13.734 & 58.86 & 74.97672 & 207.6855 \\
20 & 9.565331 & 13.734 & 58.86 & 82.15933 & 455.9843 \\
30 & 21.54786 & 13.734 & 58.86 & 94.14186 & 784.2017 \\
40 & 38.3303 & 13.734 & 58.86 & 110.9243 & 1232.369 \\
50 & 59.82642 & 13.734 & 58.86 & 132.4204 & 1837.995 \\
\hline
\end{tabular}

Berdasarkan Tabel 2, untuk mencapai kecepatan $50 \mathrm{~km} / \mathrm{jam}$ dibutuhkan daya sebesar 1837.995 W. Pada perlombaan KMHE kecepatan kendaraan berkisar antara 20-30 km/jam, daya yang dibutuhkan adalah sekitar $455.9843 \mathrm{~W}-784.2017 \mathrm{~W}$. Selain data pada Tabel 2, perlu juga diketahui torsi minimal yang diperlukan untuk menggerakkan kendaraan dengan rumus:

$$
P=T x \frac{2 \pi \omega}{60}
$$

Kecepatan sudut/putaran mesin diasumsikan berdasarkan hasil tes $400 \mathrm{rpm}$ pada kecepatan $20 \mathrm{~km} / \mathrm{jam}$ dan $600 \mathrm{rpm}$ pada $30 \mathrm{~km} / \mathrm{jam}$, maka didapat data torsi yang dibutuhkan (Tabel 3). 
Tabel 3 Data Kebutuhan Torsi Mobil (Carryer et al. 2011)

\begin{tabular}{|c|c|c|c|}
\hline$V(\mathrm{~km} / \mathrm{jam})$ & $P$ (Watt) & $\omega(\mathrm{rpm})$ & $T(\mathrm{Nm})$ \\
\hline 10 & 207.6855 & 200 & 9.91 \\
\hline 20 & 455.9843 & 400 & 10.88 \\
\hline 30 & 784.2017 & 600 & 12.48 \\
\hline 40 & 1232.369 & 700 & 16.81 \\
\hline 50 & 1837.995 & 900 & 19.5 \\
\hline
\end{tabular}

Terdapat beberapa jenis motor DC, namun motor listrik yang paling efisien adalah Brushless Direct Current atau biasa disebut BLDC, sehingga dipilih motor BLDC karena membutuhkan arus listrik DC 3 gelombang fase (Haryadi 2012). Lithium-Ion digunakan sebagai baterai untuk power supply karena baterai ini memiliki massa yang ringan, namun dapat menghasilkan energi yang lebih besar, di dalam baterai ini memakai senyawa lithium interkalasi sebagai bahan elektrodanya, berbeda dengan lithium metalik yang dipakai baterai lithium nonisi ulang (Afif dan Pratiwi 2015). Eksperimen yang dilakukan adalah dengan model simulasi untuk mendapatkan karakteristik Motor BLDC menggunakan salah satu software dari MATLAB yaitu Simulink sehingga model yang dibuat dapat dikalkulasikan rancangan modelnya melalui software dan hardware (Arifin dan Amir 2010). Sistem kontrol PID digunakan pada sistem Simulink sebagai kompensator atau suatu alat yang digunakan untuk kompensasi, yaitu memodifikasi suatu sistem yang dinamik sehingga memiliki spesifikasi yang kita inginkan, kontrol PID dapat dipahami sebagai sistem pengendali yang memperhitungkan kesalahan atau error yang terjadi pada masa sekarang, lampau dan juga di masa depan (Mituhiko 1971).

Pada penelitian yang dilakukan, dirancang bentuk sistem kelistrikan mobil hemat energi dan juga dibuat sistem simulasi Simulink MATLAB R2020b, kemudian dianalisis serta diperhitungkan data yang diperoleh. Pada sistem simulasi Simulink kontrol PID diletakkan di bagian awal sebelum memasuki sistem plant yaitu motor BLDC. Hal ini agar setelah nilai sinyal masuk ke BLDC kemudian keluar output dan kemudian diukur dengan sensor maka feedback masuk ke kontrol PID sebagai referensi perubahan yang kemudian akan mengurangi kesalahan pada masa sekarang, sebelum dan juga di masa depan (Gambar 2).

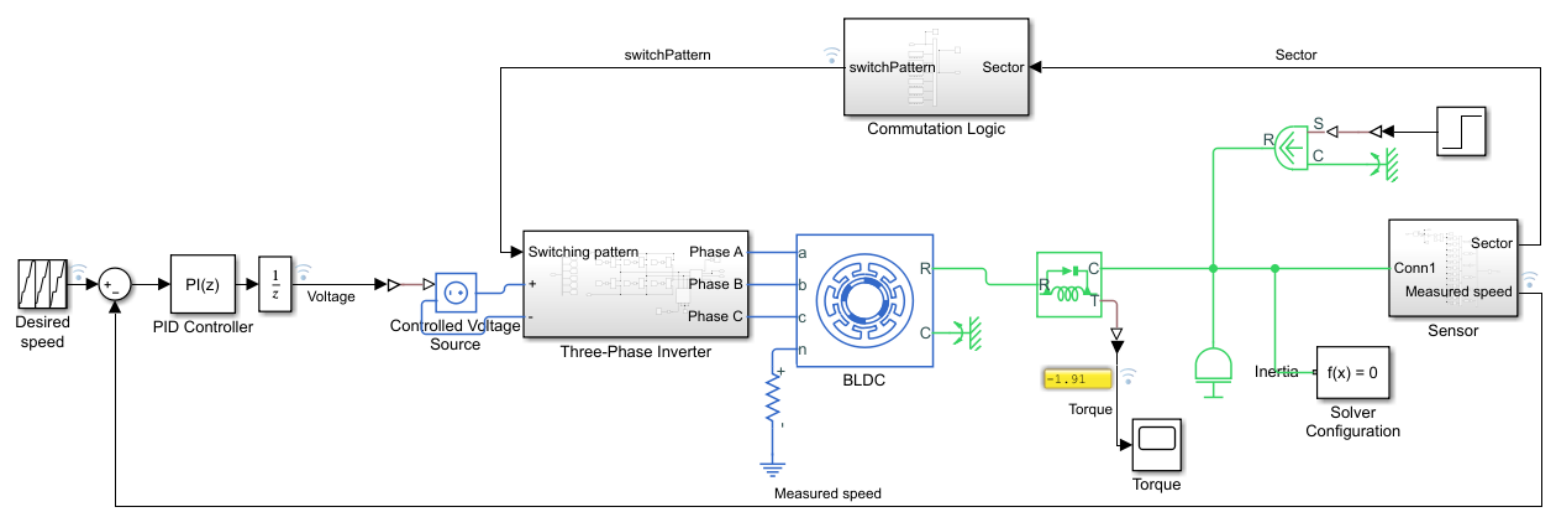

Gambar 2 Diagram Blok Kontroler PID pada Motor BLDC.

Pengujian dilakukan dengan mengikuti model matematis yang terdapat pada Simulink Matlab R2020b (Mathworks 2020), sehingga dapat diperkirakan keakuratan simulasi yang dilakukan. Berdasarkan analisis yang dilakukan dapat diasumsikan (Yue dan Bai 2014) bahwa: (1) Stator dengan lilitan $60^{\circ}$ memiliki full-pitch winding, (2) Efek slot dan saturasi magnetik sirkuit tidak dipertimbangkan, (3) Kelambatan magnet, aliran turbulen, efek dari kumpulan kulit tembaga, dan dampak pada parameter suhu dapat diabaikan, (4) Belitan stator tiga fase berbentuk simetris, $R_{a}=R_{b}=R_{c}=R, L_{a}=L_{b}=L_{c}=L, M_{a b}=M_{b c}=M_{c a}=M$. 
Setiap resistansi dilambangkan $R$, untuk setiap induktansi dilambangkan $L$, dua induktansi yang saling berdekatan dilambangkan $M$. Persamaan keseimbangan tegangan stator tiga fase dapat dinyatakan dengan Persamaan 7.

$\left[\begin{array}{l}U_{a} \\ U_{b} \\ U_{c}\end{array}\right]=\left[\begin{array}{ccc}R & 0 & 0 \\ 0 & R & 0 \\ 0 & 0 & R\end{array}\right]\left[\begin{array}{c}i_{a} \\ i_{b} \\ i_{c}\end{array}\right]+\left[\begin{array}{ccc}L & M & M \\ M & L & M \\ M & M & L\end{array}\right] P\left[\begin{array}{l}i_{a} \\ i_{b} \\ i_{c}\end{array}\right]+\left[\begin{array}{l}e_{a} \\ e_{b} \\ e_{c}\end{array}\right]+\left[\begin{array}{l}U_{n} \\ U_{n} \\ U_{n}\end{array}\right]$

Karena dalam motor listrik tiga fase yang simetris terdapat $i_{a}+i_{b}+i_{c}=0$, maka $M i_{a}+M i_{b}+M i_{c}=0$, maka dari itu persamaan keseimbangan tegangan ditunjukan pada Persamaan 8.

$\left[\begin{array}{l}U_{a} \\ U_{b} \\ U_{c}\end{array}\right]=\left[\begin{array}{lll}R & 0 & 0 \\ 0 & R & 0 \\ 0 & 0 & R\end{array}\right]\left[\begin{array}{c}i_{a} \\ i_{b} \\ i_{c}\end{array}\right]+\left[\begin{array}{ccc}L-M & 0 & 0 \\ 0 & L-M & 0 \\ 0 & 0 & L-M\end{array}\right] P\left[\begin{array}{l}i_{a} \\ i_{b} \\ i_{c}\end{array}\right]+\left[\begin{array}{l}e_{a} \\ e_{b} \\ e_{c}\end{array}\right]+\left[\begin{array}{l}U_{n} \\ U_{n} \\ U_{n}\end{array}\right]$

Torsi elektromagnetik dari BLDC dihasilkan oleh interaksi arus pada lilitan stator dan medan magnet pada magnet rotor. Persamaan torsi elektromagnetik ditunjukan pada Persamaan 9.

$$
T_{e}=\frac{1}{\omega}\left(e_{a} i_{a}+e_{b} i_{b}+e_{c} i_{c}\right)
$$

Persamaan gerak mekanik motor ditampilkan pada Persamaan 10.

$$
T_{e}-T_{L}-B_{\omega}=J \frac{d \omega}{d t}=J P \omega
$$

dengan $T_{e}$ adalah torsi elektromagnetik, $T_{L}$ adalah beban torsi, $B$ adalah koefisien redaman, $\omega$ adalah kecepatan motor, $J$ adalah inersia rotasi rotor dan beban. Maka, dapat ditetapkan model matematika lengkap dari motor BLDC.

\section{HASIL DAN PEMBAHASAN}

Model simulasi sistem kendali ini menggunakan rancangan kendali loop tertutup. Link arus listrik menggunakan PID regulator. Regulator PID memiliki keunggulan algoritma sederhana, presisi tinggi, keandalan yang kuat untuk sistem kontrol yang dapat membentuk model matematika yang tepat.

Pada motor BLDC gelombang yang dihasilkan yaitu berupa gelombang yang berbentuk trapezoidal pada back-EMF, yang dikontrol oleh trapezoidal control (Gambar 3).

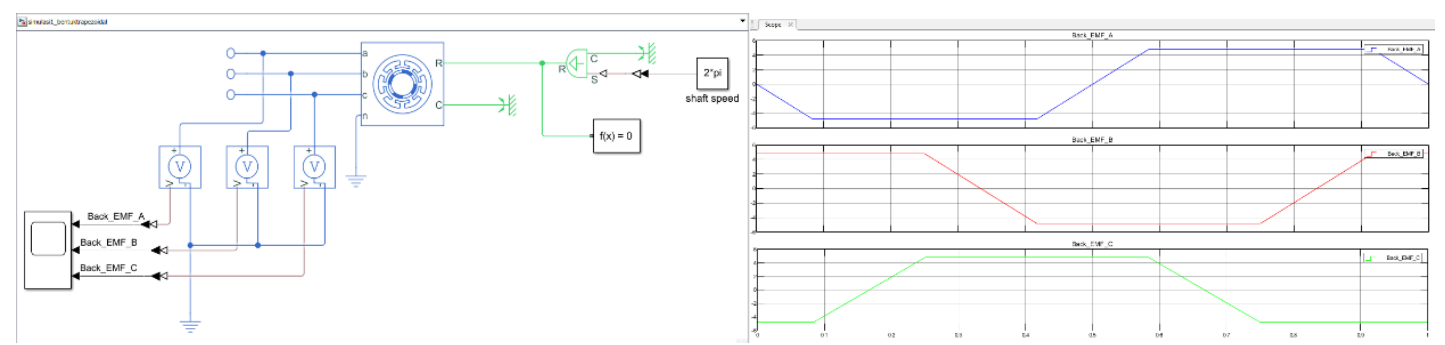

Gambar 3 Sistem Simulink dan Hasil Bentuk Gelombang Tiap Fase Motor BLDC.

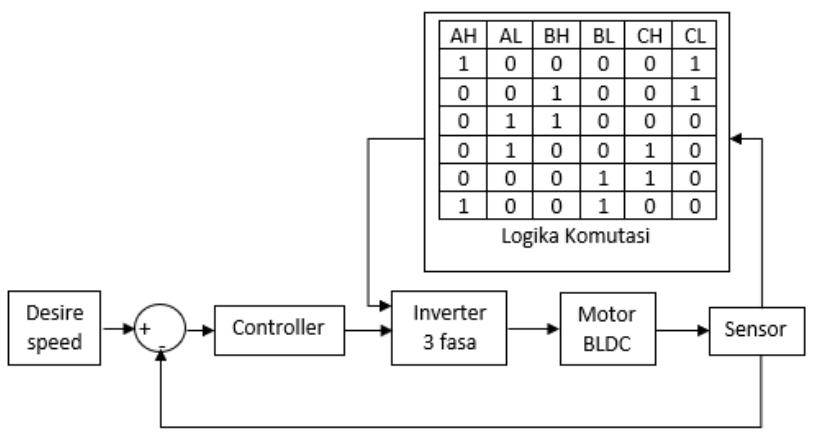

Gambar 4 Bentuk Teknik Kontrol yang Dilakukan pada Motor BLDC. 
Pada Gambar 4 sistem logika komutasi digunakan untuk mengontrol motor BLDC, desired speed yang diinginkan berasal dari pedal potensiometer yang digunakan oleh pengemudi, kemudian akan diterima oleh kontroler yang kemudian digunakan untuk mengubah pattern dari inverter 3 fase yang akan menggerakan motor BLDC.

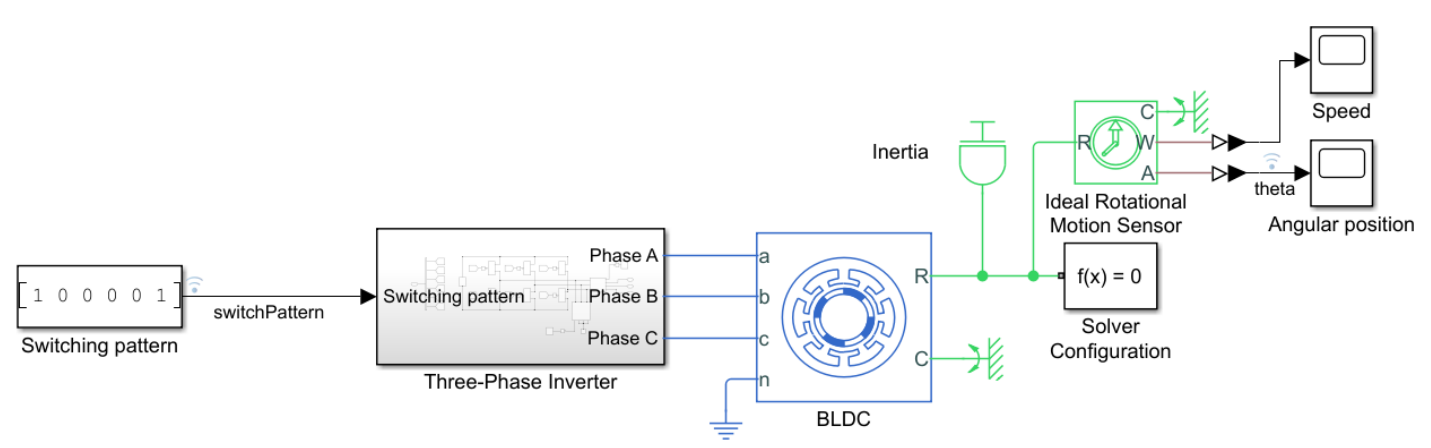

Gambar 5 Sistem Simulink dengan Inverter Tiga Fase.

Gambar 5 menunjukkan Simulink switching pattern diberikan pada Simulink motor BLDC, sehingga motor dapat bergerak sesuai dengan step komutasi, melalui switching pattern ditentukan jenis IC mosfet yang akan on/off pada inverter tiga fase sehingga motor BLDC akan berputar sesuai dengan posisi rotor yang ada. Parameter tegangan yang diberikan pada inverter tiga fase adalah $48 \mathrm{~V}$.

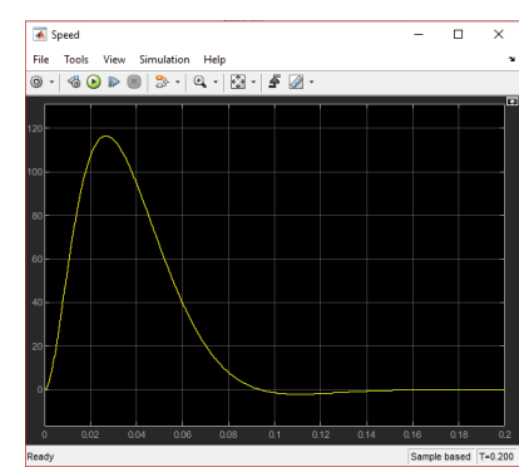

(a)

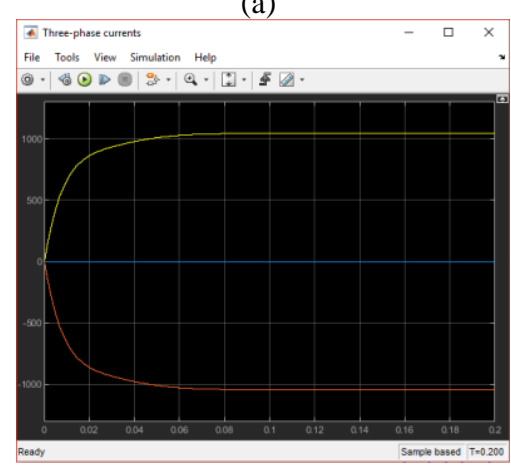

(c)

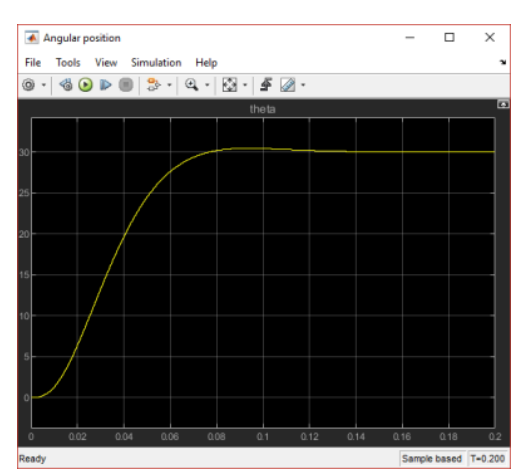

(b)

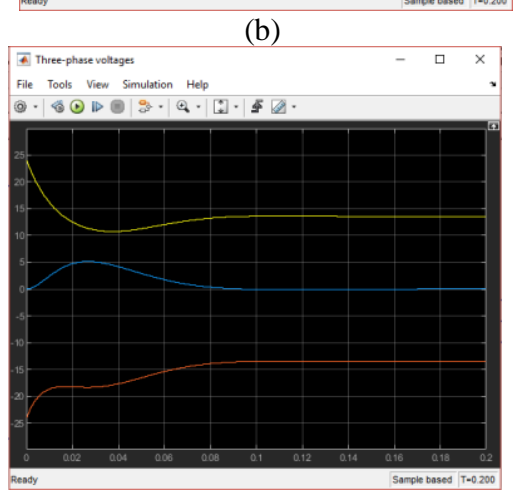

(d)

Gambar 6 Hasil Pada Scope (a) Speed, (b) Angular Position, (c) Arus 3 Fase, (d) Tegangan 3 Fase.

Pada Gambar 6 dapat dilihat hasil respon sistem pada scope, pada respon speed (Gambar 6 (a)) terlihat memiliki rising time yang baik, tidak adanya overspeed pada motor. Pada respon Angular Position Gambar 6 (b) berada di $30^{\circ}$ sesuai dengan six step komutasi dan rising time yang baik $0,08 \mathrm{~s}$ dan settling time yang stabil. Pada respon Arus dan Tegangan Gambar 6 (c,d) digunakan $1000 \mathrm{~mA}$ atau $1 \mathrm{~A}$ untuk bekerja dan grafik tegangan dapat dilihat hanya pole A dan $\mathrm{C}$ yang diberikan tegangan. Overcurrent dan overvoltage tidak terjadi. 


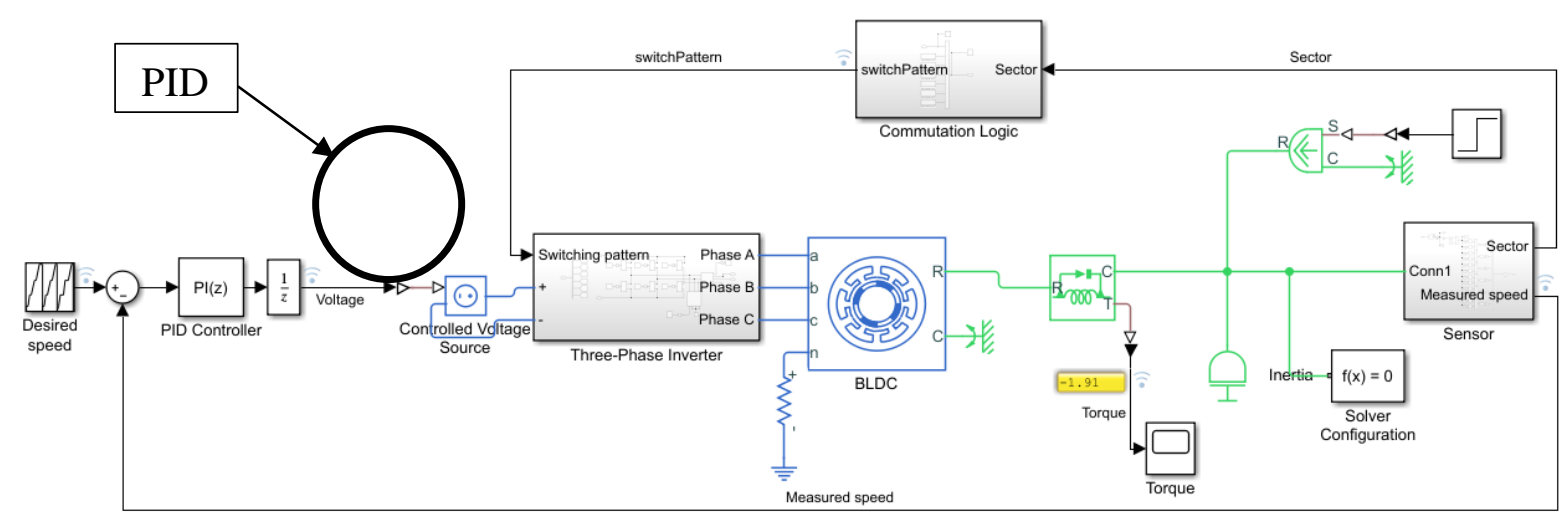

Gambar 7 Sistem Simulink Dengan PID dan Logika Komutasi.

Pada Gambar 7 dapat dilihat bahwa sistem Simulink yang ada diberikan kontroler PID, hal tersebut agar mendapatkan hasil terbaik yang dapat dilihat, sehingga respon sistem akan semakin mendekati keadaan aslinya.

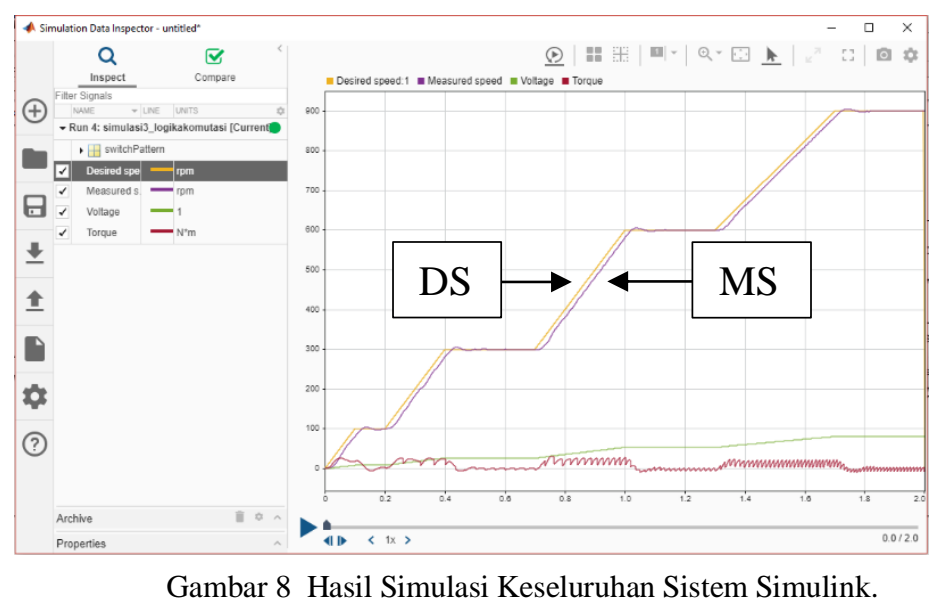

Pada Gambar 8 dapat dilihat bahwa desired speed (DS) dan juga measured speed (MS) memiliki error yang kecil sehingga dapat disimpulkan bahwa dengan menggunakan sistem PID maka motor BLDC dapat bekerja dengan baik.

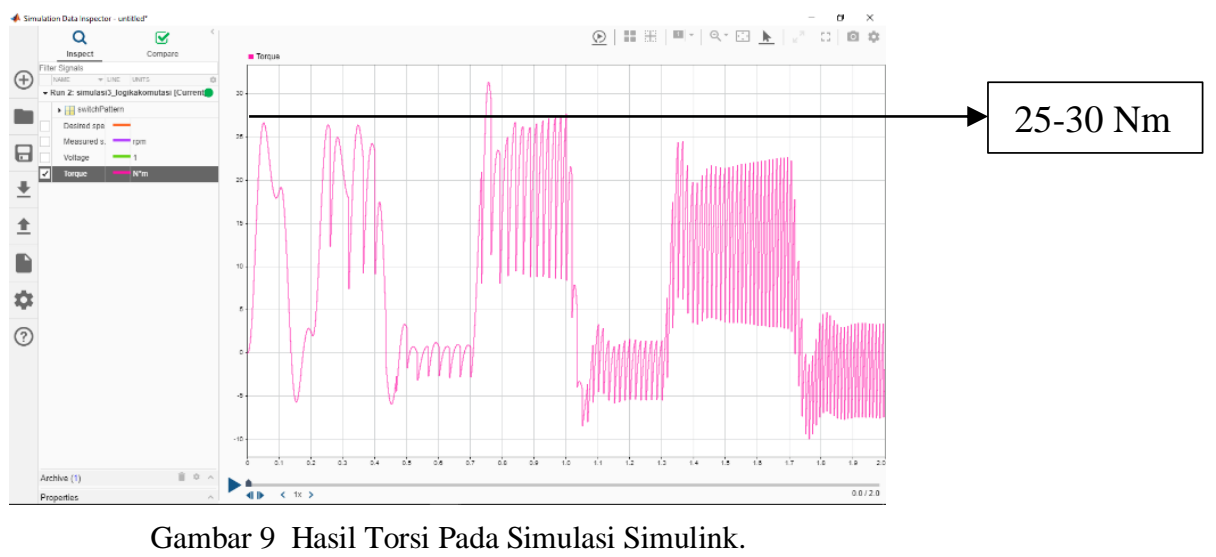

Pada Gambar 9 dapat dilihat bahwa dengan menggunakan motor BLDC torque yang dihasilkan pada simulasi Simulink MATLAB sekitar $30 \mathrm{Nm}$, maka dapat disimpulkan motor BLDC dapat digunakan untuk menjalankan mobil listrik yang diperhitungkan membutuhkan 10,88 Nm - 12,48 Nm untuk dapat bergerak dengan bobot mobil sekitar $200 \mathrm{~kg}$ (Tabel 3). Melalui simulasi yang telah dilakukan didapatkan sejumlah data yaitu motor BLDC 
membutuhkan tegangan $48 \mathrm{~V}$ dan 1 A untuk dapat berjalan, bila dirumuskan dengan rumus daya pada rangkaian listrik, maka daya dapat dihitung dengan menggunakan Persamaan 11.

$$
\begin{aligned}
\mathrm{P}(\text { daya }) & =\mathrm{V}(\text { Voltase }) \times \mathrm{I}(\text { Ampere }) \\
\mathrm{P} & =48 \mathrm{~V} \times 1 \mathrm{~A}=48 \mathrm{~W}
\end{aligned}
$$

Daya yang dihasilkan pada rancangan motor BLDC yang berspesifikasi $48 \mathrm{~V}$ dan baterai yang tersedia 20 A dapat dihitung dengan menggunakan persamaan 11, sehingga menghasilkan daya sebesar $960 \mathrm{~W}$.

$$
\mathrm{P}=48 \mathrm{~V} \times 20 \mathrm{~A}=960 \mathrm{~W}
$$

Berdasarkan hasil perhitungan tersebut dapat disimpulkan bahwa rancangan baterai yang digunakan memenuhi syarat untuk dapat digunakan.

Respon sistem pada motor BLDC juga terlihat baik dengan menggunakan kontroler PID, melalui sistem kontrol PID diatur voltase dan arus yang digunakan oleh inverter tiga fase, lalu voltase dan arus listrik masuk ke motor BLDC sehingga motor bergerak. Kemudian sensor melakukan feedback sehingga dapat diketahui hasil kecepatan yang kemudian akan digunakan untuk memperbaiki error yang terjadi secara berulang menghasilkan sistem kontrol yang baik untuk penggunaan motor BLDC.

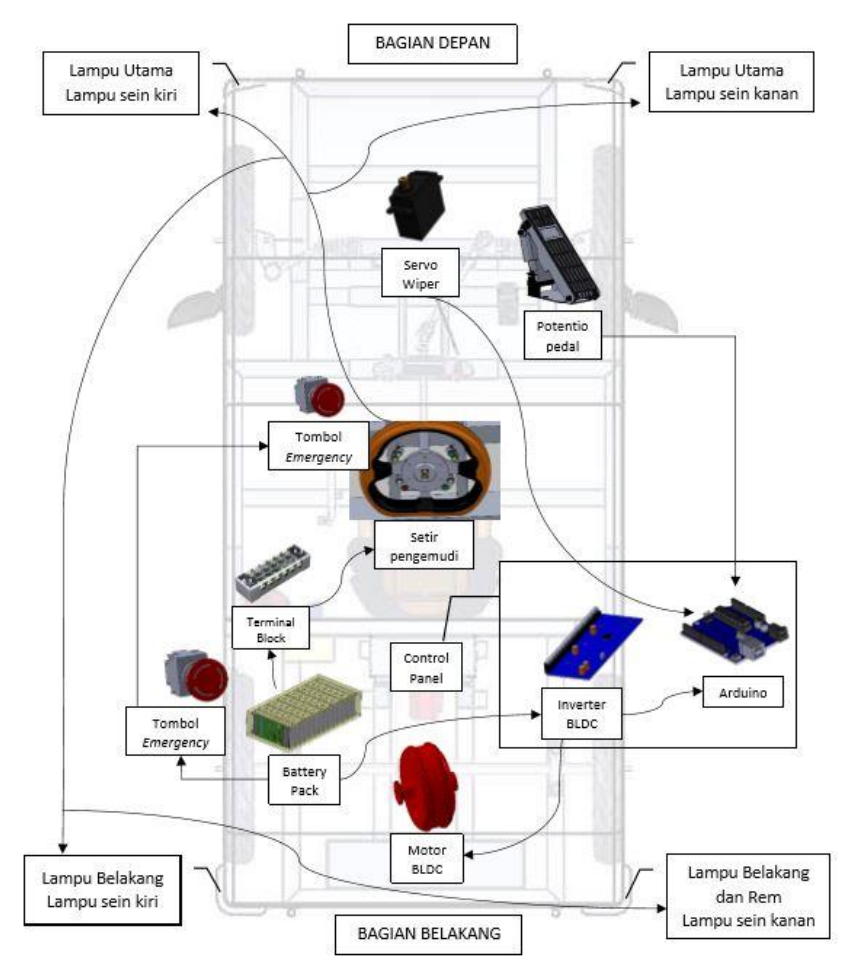

Gambar 10 Diagram Keseluruhan Sistem Kelistrikan.

Pada Gambar 10 dapat dilihat diagram kelistrikan keseluruhan pada mobil listrik yang telah disesuaikan dengan regulasi KMHE 2019 telah dirancang. Tabel 4 menunjukkan tipe dari komponen beserta penjelasannya.

Tabel 4 Spesifikasi Komponen Sistem Kelistrikan

\begin{tabular}{clll}
\hline No. & \multicolumn{1}{c}{ Model data } & \multicolumn{1}{c}{ Spesifikasi } & \multicolumn{1}{c}{ Penjelasan } \\
\hline 1 & Motor BLDC & Elektrikal: & Motor BLDC dipilih karena efisiensinya \\
& (Brushless Direct & - Daya : $1000 \mathrm{~W}$ & yang lebih baik dibandingkan dengan \\
& Current $)$ & - Voltase : 48 V & motor AC, hal ini dikarenakan \\
Tipe : & - Over Power Watt pada 1500 W & penyimpanan listrik berupa arus DC, \\
LL18125095 & - Ampere Kerja : 25-30 A & sehingga tidak perlu mengubah arus DC \\
& & - OverAmpere maksimal pada 40 A & tersebut, sedangkan jika menggunakan \\
& & - Recommend kontroler 48 V, 1000 W, 35A & motor AC maka dibutuhkan inverter DC \\
& & - Minimum kontroler 48 V 1000 W 32 A & ke AC sehingga akan terjadi heat loss \\
& & - Maksimum kontroler 48 V 1500 W 45 A & pada saat perubahan arus DC ke AC \\
& &
\end{tabular}




\begin{tabular}{|c|c|c|c|}
\hline No. & Model data & Spesifikasi & Penjelasan \\
\hline & & $\begin{array}{l}\text { Mekanis: } \\
\text { - Berat : 7-8 kg } \\
\text { - Ring roda compatible : 14", 17" dan 20", } \\
\text { 24”, 26", } 27.5 " \\
\text { - Opensize as : Fix on size MTB (Mountain } \\
\text { Bike), minimal } 13.5 \mathrm{~cm} \text {, support hingga } 15 \\
\text { cm } \\
\text { - Total panjang as : } 20 \mathrm{~cm} \\
\text { - Bearing : tertutup/sealed } \\
\text { - Top speed : } 55-60 \mathrm{~km} / \mathrm{jam}, 600 \mathrm{rpm} \\
\text { - Torsi : } 30 \mathrm{Nm}-50 \mathrm{Nm} \\
\text { - Fitur Dinamo : Support Controller REGEN } \\
\text { (putaran clockwise dan counter-clockwise) } \\
\text { - Hall sensor : Standar hall sensor } \\
\text { - Socket : socket pin isi } 5 \text { untuk hall, dan } 3 \\
\text { socket untuk fase. }\end{array}$ & $\begin{array}{l}\text { motor BLDC memiliki torsi yang tinggi } \\
\text { dengan kebutuhan tenaga } 48 \mathrm{~V} \text { sudah } \\
\text { dapat menghasilkan torsi sebesar } 30 \mathrm{Nm} \\
\text { jika dibandingkan motor DC biasa dan } \\
\text { juga motor AC. Harga motor BLDC } \\
\text { relatif lebih mahal karena desain yang } \\
\text { kompleks dibandingkan motor listrik AC, } \\
\text { namun tidak membutuhkan perawatan } \\
\text { karena menggunakan bearing sebagai } \\
\text { tumpuannya, tidak menggunakan sikat } \\
\text { commutator atau brush. }\end{array}$ \\
\hline 2 & $\begin{array}{l}\text { Controller DC } \\
\text { Inverter } 3 \text { fase }\end{array}$ & $\begin{array}{l}\text { - Berat : } 1-2 \mathrm{~kg} \\
\text { - Kebutuhan : } 12 \mathrm{~V}-48 \mathrm{~V} \\
\text { - Pengatur kecepatan: potentiometer pedal } 12 \mathrm{~V} \\
\text { - Current limit : } 48 \mathrm{~V} \\
\text { - DC-DC converter : > } 60 \mathrm{~V} \text { diubah ke } 12-48 \mathrm{~V} \\
\text { - Mosfet controller : P-channel dan N-Channel } \\
\text { mosfet }\end{array}$ & $\begin{array}{l}\text { Controller ini digunakan untuk mengubah } \\
\text { dan membagi arus menjadi tiga fase dan } \\
\text { dialirkan pada masing-masing kumparan } \\
\text { sesuai dengan posisi dari hall sensor. }\end{array}$ \\
\hline 3 & $\begin{array}{l}\text { Controller } \\
\text { Arduino Uno } \\
\text { Atmega328 }\end{array}$ & $\begin{array}{l}\text { - Catu Daya } 7 \text { V - } 12 \text { V DC } \\
\text { - Berbasis mikroprosesor: Atmega328 } \\
\text { - Jumlah Port I/O : } 14 \text { pin I/O (6 pin untuk } \\
\text { output PWM) dan Analog Input } 5 \text { pin } \\
\text { - Port antarmuka : UART TTL, I2C, SPI dan } \\
\text { USB (Virtual Com) }\end{array}$ & $\begin{array}{l}\text { Arduino Uno dipilih karena kebutuhan } \\
\text { untuk mengatur wiper, mengatur input } \\
\text { sinyal analog dari potentiopedal. Harga } \\
\text { juga relatif lebih murah dari ECU (Engine } \\
\text { Control Module) untuk mobil } \\
\text { konvensional. }\end{array}$ \\
\hline 4 & $\begin{array}{l}\text { Baterai Pack } \\
\text { Lithium-Ion } \\
\text { NCR18650 14s7p }\end{array}$ & $\begin{array}{l}\text { - Berat : } 5 \mathrm{~kg} \\
\text { - Volume }(p \times l \times t): 20 \mathrm{~cm} \times 12 \mathrm{~cm} \times 10 \mathrm{~cm} \\
\text { - Kapasitas : } 57,4 \mathrm{~V}(\text { normal }) \text { hingga } 60 \mathrm{~V} \\
\text { (overcharge }), 60 \mathrm{~V} \text { maksimal } \\
\text { - Isi : Lithium-ion } 14 \mathrm{~s} 7 \mathrm{p} \text { (dirangkai secara } 14 \\
\text { seri dan } 7 \text { paralel), kapasitas baterai Li-Ion } \\
4.1 \mathrm{~V} / \mathrm{pcs} \\
\text { - Pengaman : BMS (Battery Management } \\
\text { System) } 7 \text { cell } \\
\text { - Temperatur : } 15^{\circ} \mathrm{C}-20^{\circ} \mathrm{C} \text { suhu saat bekerja } \\
\text { - Charge time : } 3-5 \mathrm{jam}\end{array}$ & $\begin{array}{l}\text { Lithium Ion NCR18650 digunakan } \\
\text { karena memiliki spesifikasi bahan } \\
\text { penyimpan listrik yang baik, mampu } \\
\text { bekerja pada suhu rendah dan juga tinggi, } \\
\text { serta jika dibandingkan dengan baterai } \\
\text { lithium polymer, jika terjadi kerusakan } \\
\text { harus mengganti keseluruhan bagian dari } \\
\text { baterai, sedangkan jika baterai Lithium } \\
\text { Ion salah satu rusak, maka dapat diganti } \\
\text { bagian yang rusak tersebut dengan baterai } \\
\text { baru tanpa mengganti keseluruhan baterai. } \\
\text { Sehingga biaya relatif murah. }\end{array}$ \\
\hline 5 & $\begin{array}{l}\text { Charger Battery } \\
\text { Pack }\end{array}$ & $\begin{array}{l}\text { - Berat : } 2-3 \mathrm{~kg} \\
\text { - Input : } 220 \mathrm{~V} \mathrm{AC} \\
\text { - Output : } 48 \mathrm{~V} \mathrm{DC} \\
\text { - Temperatur kerja : } 25^{\circ} \mathrm{C}-28^{\circ} \mathrm{C} \\
\text { - Indikator led : red (active) }\end{array}$ & $\begin{array}{l}\text { Charger dibuat agar ketika mobil } \\
\text { membutuhkan sumber daya maka sudah } \\
\text { memiliki alat untuk mengisi kembali, } \\
\text { tanpa perlu mencari atau membeli } \\
\text { charger dengan spesifikasi yang cocok } \\
\text { dengan baterai yang digunakan }\end{array}$ \\
\hline 6 & $\begin{array}{l}\text { Emergency Stop } \\
\text { Switch Push } \\
\text { Button Mushroom }\end{array}$ & $\begin{array}{l}\text { - Dua switch sirkuit : } 1 \text { Normally Open, } 1 \\
\text { Normally Closed (DPST: Double Pole Single } \\
\text { Throw) } \\
\text { - Jumlah terminal pin : } 4 \text { pin } \\
\text { - Kontak rate }: 600 \mathrm{~V} / 10 \mathrm{~A}\end{array}$ & $\begin{array}{l}\text { Emergency push button digunakan untuk } \\
\text { memberi pengamanan terhadap sistem } \\
\text { dan juga pengendara, sehingga } \\
\text { pengemudi dapat memutus kontak dari } \\
\text { sumber daya ke seluruh sistem listrik di } \\
\text { mobil. }\end{array}$ \\
\hline 7 & $\begin{array}{l}\text { Motor Servo } \\
\text { MG996R Micro } \\
\text { Metal Servo }\end{array}$ & $\begin{array}{l}\text { - Berat : } 55 \mathrm{~g} \\
\text { - Torsi : } 9,4 \mathrm{kgfcm}(4,8 \mathrm{~V}), 11 \mathrm{kgfcm}(6 \mathrm{~V}) \\
\text { - Sudut : maksimal } 120^{\circ} \\
\text { - Operating speed : } 0,17 \mathrm{~s} / \mathrm{d} 60(4,8 \mathrm{~V}), 0,14 \\
\text { - } / \mathrm{d} 60(6 \mathrm{~V}) \\
\text { - Operating voltage }: 4,8 \mathrm{~V}-7,2 \mathrm{~V} \\
\text { - Running Current } 500 \mathrm{~mA} 900 \mathrm{~mA}(6 \mathrm{~V}) \\
\end{array}$ & $\begin{array}{l}\text { Servo dipilih untuk menggerakkan wiper } \\
\text { karena sudut putaran dari servo dapat } \\
\text { diatur, sehingga dapat memudahkan } \\
\text { teknisi untuk mengatur range swipe dari } \\
\text { wiper agar pengemudi dapat dengan baik } \\
\text { membersihkan pandangan di dalam } \\
\text { mobil. }\end{array}$ \\
\hline
\end{tabular}

Pada sistem kerja bagaimana motor BLDC dapat bekerja dan komponen yang digunakan dapat dilihat pada Gambar 11. 


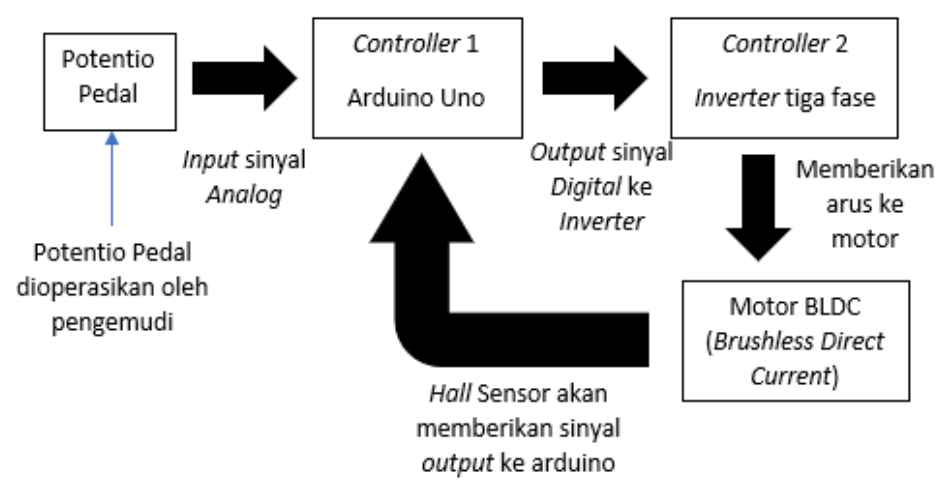

Gambar 11 Diagram Sistem Kerja Motor BLDC.

Pada Gambar 11 dijelaskan bahwa potensiopedal yang dioperasikan oleh pengemudi akan diberikan arus listrik sehingga nilai resistansinya dapat diterima oleh controller 1 Arduino sebagai input analog, kemudian dikonversikan pada Arduino dengan bahasa pemrograman C\#, didapatkan nilainya dari 0-255. Melalui Arduino nilainya dikirimkan ke controller 2 agar dapat membuka aliran listrik dari mosfet yang terdapat pada inverter tiga fase, melalui mosfet tersebut arus listrik DC masuk ke 3 bagian coil yang terhubung pada motor BLDC, sehingga motor BLDC dapat berputar. Kemudian, posisi rotor BLDC dapat dicek dengan hall sensor yang akan masuk ke controller 2 BLDC, sinyal dari hall sensor juga akan masuk ke arduino sebagai sinyal analog yang kemudian dapat diketahui nilainya di Arduino.

\section{SIMPULAN DAN SARAN}

Berdasarkan penelitian dan analisis yang telah dilakukan terhadap pengujian simulasi dengan software Simulink di MATLAB dan desain sistem kelistrikan yang diperlihatkan melalui gambaran dengan aplikasi Solidworks dan juga dengan wiring diagram keseluruhan sistem dapat disimpulkan bahwa telah berhasil dibuat dan disimulasikan penggunaan motor BLDC sebagai penggerak mobil listrik dengan Simulink MATLAB yang mengukur torsi motor BLDC yang dimiliki tim WSM. Pada motor BLDC memiliki hasil torsi sebesar $30 \mathrm{Nm}$ dan daya sebesar $960 \mathrm{~W}$, sudah melebihi perhitungan torsi yang dibutuhkan sekitar 10,88 Nm $12,48 \mathrm{Nm}$. Juga telah berhasil dirancang sistem kelistrikan mobil hemat energi yang sesuai dan memenuhi kriteria regulasi KMHE 2019.

Saran yang dapat diberikan yaitu secara spesifik kesulitan pada penelitian ini adalah membutuhkan waktu yang lama untuk dapat merancang sistem Simulink dengan PID sekitar 45 bulan dan juga pada kondisi pandemik seperti sekarang ini sulit untuk medapatkan informasi lebih yang dapat dituangkan pada penelitian ini.Lebih baik lagi simulasi dilakukan di institusi pengujian teknologi sehingga hasil simulasi pada Simulink di MATLAB dapat dibandingkan dengan hasil eksperimen sehingga dapat diketahui galatnya.

\section{DAFTAR PUSTAKA}

Acosta B, Betancourt M, Pinheiro F. Shell eco-marathon $100 \%$ of final report [tesis]. Florida (US): Florida International University.

Afif MT dan Pratiwi IAP. 2015. Analisis perbandingan baterai Lithium-Ion, Lithium-Polymer, Lead Acid dan Nickel-Metal Hydride pada penggunaan mobil listrik - review. Jurnal Rekayasa Mesin. 6(2): 95-99.

Arifin Y dan Amir A. 2010. Pemodelan dan pengendalian motor DC menggunakan simulasi MATLAB. Majalah Ilmiah MEKTEK. 12(2): 129-137.

Carryer JE, Ohline RM, Kenny TW. 2011. Introduction to Mechatronic Design. New Jersey (US): Prentice Hall.

Haryadi D. 2012. Studi pemilihan motor DC dan kapasitasnya pada mobil listrik. Palembang (ID): Universitas Sriwijaya. 
Madur S and Debre A. 2017. Brushless Direct Current Motor (BLDC) for electric vehicles. International Journal on Recent Innovation in Instrumentation \& Control Engineering. $1(1): 15-18$.

Mathworks. 2020. Power electronics control design with simulink [Internet]. [Diunduh 2020 Feb 08]; https://www.mathworks.com/solutions/power-electronics-control/bldc-motorcontrol.html

Mituhiko A. 1971. PID control [Internet]. [Diunduh 2020 Jan 03]; http://gpdlpune.ac.in/ mainEN/IAM/E6-43-03-03.pdf

Universitas Negeri Malang. 2019. Regulasi teknis KMHE 2019 [Internet]. [Diunduh 2020 Jan 03]; http://kmhe2019.um.ac.id/.

Yue XL and Bai P. 2014. Modelling and simulation of brushless DC motor speed control system based on MATLAB/SIMULINK. Advanced Materials Research. 998(999): 755-758. 